\title{
"NÃO HÁ MAIS CHANCE DE NÃO QUERER SEGUIR ESTE CAMINHO": GRAFIAS DE UMA GERAÇÃO DE JOVENS NA UNIVERSIDADE PÚBLICA
}

\author{
Érica Peçanha do Nascimento ${ }^{1}$
}

\begin{abstract}
RESUMO
Tendo como referência comunicações pessoais e textos produzidos por graduandos na condição de pesquisadores de um projeto de pesquisa e extensão, este artigo busca refletir como marcadores de idade, geração, classe social, raça e território se articulam na experiência universitária, e influem na percepção desses jovens sobre si mesmos e seus projetos de vida. Com o aporte de outros trabalhos antropológicos que tomaram documentos e escritos em torno da vida pessoal e profissional como objetos de análise (KOFES; MANICA, 2015), investe-se aqui numa narrativa etnográfica sobre esses jovens e sua geração, produzida no encontro de minha narrativa pessoal como pesquisadora-supervisora do projeto em foco e as narrativas produzidas pelos graduandos sobre si mesmos, a participação no projeto e a universidade pública. As diferentes fontes mobilizadas para este trabalho (currículo, relatório de pesquisa e relato com fins de publicação) são lidas a um só tempo como narrativas autobiográficas e grafias da vida social de certa parcela da juventude brasileira, cuja experiência geracional passa também pelo acesso à universidade em contexto recente.
\end{abstract}

\section{PaLAVRAS-CHAVE}

Antropologia da juventude; Jovens periféricos; Universidade pública.

\section{"THERE IS NO MORE CHANCE OF REJECTING THIS PATH": WRITINGS OF A GENERATION OF YOUNG STUDENTS WITHIN PUBLIC UNIVERSITIES}

\begin{abstract}
Drawing from personal communications and the texts produced by undergraduates working for a research and extension project, this article aims to reflect on how age, generation, social class, race and territory are articulated in the university experience, and to what extent they affect the perception of these young students about themselves and their life projects. Based on the contribution of other anthropological works which took documents and writings around personal and professional life as objects of analysis (KOFES; MANICA, 2015), I present an ethnographic narrative about these youngsters and their generation in conversation with my own narrative as the researcher-supervisor of the project and those produced by the undergraduates about themselves, their participation in the project, and the public university as a whole. The different sources mobilized for this work (curriculum, research report and publishing report) are read at the same time as autobiographical narratives and writings of the social life of a specific portion of Brazilian youth, whose generational experience also involves access to the university in recent contexts.
\end{abstract}

KEYWORDS

Anthropology of youth; Peripheral youth; Public university.

\footnotetext{
${ }^{1}$ Antropóloga, pesquisadora de pós-doutorado do Instituto de Estudos Avançado da Universidade de São Paulo (IEA-USP) e do nPeriferias - Grupo de Pesquisa das Periferias.
} 


\title{
"IL N'Y A PLUS AUCUNE CHANCE DE NE PAS VOULOIR SUIVRE CETTE VOIE": ORTHOGRAPHES D'UNE GENERATION DE JEUNES DANS LES UNIVERSITES PUBLIQUES
}

\section{RÉSUMÉ}

À partir de communications personnelles et de textes produits par des étudiants de premier cycle en tant que chercheurs d'un projet de recherche et d'extension, cet article cherche à réfléchir sur la façon dont les marqueurs d'âge, de génération, de classe sociale, de race et de territoire s'articulent dans l'expérience universitaire, et influencent leur perception des jeunes sur eux-mêmes et leurs projets de vie. Avec le soutien d'autres travaux anthropologiques qui ont pris comme objets d'analyse des documents et écrits autour de la vie personnelle et professionnelle (KOFES; MANICA, 2015), on investit dans un récit ethnographique sur ces jeunes et leur génération, produit à la rencontre de mon récit personnel en tant que chercheure-superviseure du projet en discussion et les récits produits par les étudiants de premier cycle sur eux-mêmes, la participation au projet et l'université publique. Les différentes sources mobilisées pour ce travail (curriculum, rapport de recherche et rapport à des fins de publication) sont lues à la fois comme des récits autobiographiques et des graphies de la vie sociale d'une certaine partie de la jeunesse brésilienne, dont l'expérience générationnelle passe aussi par l'accès à l'université en un contexte récent.

\section{MOTS-CLÉS}

Anthropologie de la jeunesse; Jeunesse périphérique; Université publique.

\section{"YA NO HAY POSIBILIDAD DE NO QUERER SEGUIR ESTE CAMINO": DELETREOS DE UNA GENERACION DE JOVENES EN LAS UNIVERSIDADES PUBLICAS}

\begin{abstract}
RESUMEN
Teniendo como referencia comunicaciones personales y textos producidos por estudiantes universitarios como investigadores de un proyecto de investigación y extensión, este artículo busca reflexionar sobre cómo los marcadores de edad, generación, clase social, raza y territorio se articulan en la experiencia universitária e influyen en su percepción sobre ellos mismos y sus proyectos de vida. Con el aporte de otros trabajos antropológicos que tomaron documentos y escritos en torno a la vida personal y profesional como objetos de análisis (KOFES; MANICA, 2015), invertimos en una narrativa etnográfica sobre estos jóvenes y su generación, producida en el encuentro de mi narrativa personal como investigadora-supervisora del proyecto en foco y las narrativas producidas por los estudiantes sobre ellos mismos, la participación en el proyecto y la universidad pública. Las diferentes fuentes movilizadas para este trabajo (currículum, informe de investigación e informe con fines de publicación) se leen al mismo tiempo que narrativas autobiográficas y gráficos de la vida social de una determinada porción de la juventud brasileña, cuya experiencia generacional también implica el acceso a la universidad en un contexto reciente.
\end{abstract}

\section{PALABRAS-CLAVE}

Antropología juvenil; Juventud periférica; Universidad pública. 


\section{INTRODUÇÃO}

Assim como é importante afirmar que idade não é um tema novo na antropologia, por operar como como princípio de organização social em sociedades tidas como tradicionais e complexas (FEIXA, 1999), é significativo considerar que grupos etários e as fases da vida a ele relacionados se tornaram centrais para pensar sistemas de classificação social, produção de corpos e identidades coletivas em estudos antropológicos². Como expressão de um conjunto de características biológicas e sociais que são comuns a uns e não a outros, idade assim como o que se convencionou categorizar como classe, raça, etnia, gênero, sexualidade etc.- pode ser lida como um marcador social que remete à produção de diferenças e desigualdades entre indivíduos e grupos. Muito embora sinalize, também, a diversidade da experiência humana e as possibilidades de vivenciá-las conforme condicionantes de tempo e de lugar.

Juventude, nesse sentido, sempre foi muito mais do que uma palavra que permite contrastar o novo e o velho. Trata-se de uma noção que sintetiza um processo de transformações físicas, psicológicas e vivências sociais relacionadas à determinada fase da vida, mas que não se restringe a um padrão único, tampouco pode ser reduzida a uma categorização etária. Nessa perspectiva sociocultural e histórica, jovens só podem ser entendidos como sujeitos concretos que vivenciam essa fase da vida de modos distintos, a despeito da multiplicidade de circunstâncias que podem caracterizar a experiência juvenil, como posição de classe, identidade de gênero, pertencimento racial, local de moradia, orientação sexual, entre outros aspectos (NOVAES, 2007; 2019).

Outra perspectiva já consolidada é que a compreensão dos jovens, nos seus diferentes modos de vivenciar a juventude, prescinde também de contextualizá-los historicamente como integrantes de uma geração específica. Isto é, como sujeitos que experimentam os mesmos problemas históricos concretos e que partilham de um conjunto de experiências comuns (MANNHEIM, 1993 [1928]; DOMINGAS; SCHIMIT, 2020).

No Brasil, as experiências de jovens pobres, negros e moradores de favelas e periferias vêm sendo apreendidas e descritas, há diferentes gerações, a partir das desigualdades de condições de vida e saúde, acesso a direitos e a oportunidades de estudo, trabalho e participação política em relação aos jovens das camadas médias e altas e brancos (FRIGOTTO, 2004; CAMACHO, 2007; GUIMARÃES, 2011). Ainda que essa mesma parcela da população tenha sido capaz de produzir e ser estudada, também, por suas formas de ação coletiva em torno de suas subjetividades e demandas, bem como expressões culturais que

\footnotetext{
${ }^{2}$ Ver, por exemplo, os trabalhos apresentados por Saggese et al. (2018).
} 
geraram signos e estilos que atravessaram fronteiras sociais e grupos etários, como o funk e o hip hop (SOUTO, 1997; FELIX, 2018). Isso porque, há décadas, são esses os jovens mais expostos à violência física e simbólica, os que estão em maior número no sistema prisional, os que ingressam mais precocemente no mercado de trabalho, os que ocupam os postos mais precários, os que mais combinam trabalho e estudo, os que acumulam menos anos escolarização e menor acesso ao ensino superior, os que experimentam mais obrigações e compromissos ligados à vida adulta em idade reduzida - para citar alguns dos indicadores que evidenciam como os marcadores sociais influem nas suas possibilidades de ser e estar no mundo.

Especificamente no que diz respeito ao acesso ao ensino superior brasileiro, acumulam-se vinte anos de debates e políticas para ingresso de negros e pobres na universidade pública, mas esse acúmulo não se mostrou suficiente para a promoção da equidade racial dentro e fora do ambiente acadêmico. São muitos os estudos que apontam a importância dessas ações para o aumento das taxas de escolarização, a mobilidade social e mesmo para os processos de identificação/pertencimento de negros e pobres. Mas também são muitos os trabalhos que vão apontar a dificuldade de permanência, o sofrimento acadêmico, as controvérsias e os desafios dessa presença de negros e pobres na universidade, em particular, na universidade pública (LOPES; BRAGA, 2007; PASSOS et. al., 2016).

Este artigo se soma a esses trabalhos no esforço de pensar os significados e desdobramentos do acesso de jovens negros e de origem popular no ensino universitário, a partir das narrativas daqueles que são também originários de periferias e favelas. Toma-se como referência informações pessoais, documentos e textos produzidos por jovens graduandos na condição de pesquisadores de um projeto de pesquisa e extensão da Universidade de São Paulo (USP) para refletir como marcadores de idade, classe social, raça e território se articulam na experiência universitária, e influem na percepção desses jovens sobre si mesmos e seus projetos de vida (VELHO, 1994; DAYRELL, 2005; PERONDI, 2020), em um contexto em que a própria USP experimenta uma mudança no perfil dos seus estudantes como efeitos de suas políticas de ação afirmativa.

As diferentes fontes mobilizadas para este texto (currículo, relatório de pesquisa e relato com fins de publicação) são lidas a um só tempo como narrativas autobiográficas e grafias da vida social de certa parcela da juventude brasileira, cuja experiência geracional passa pelo acesso à universidade em contexto recente. Com o aporte de outros trabalhos antropológicos que tomaram documentos e escritos em torno da vida pessoal e profissional como objetos de análise (KOFES; MANICA, 2015), investe-se aqui numa narrativa etnográfica sobre esses jovens e sua geração, produzida no encontro de minha narrativa pessoal como 
pesquisadora-supervisora do projeto em foco e as narrativas produzidas pelos graduandos sobre si mesmos, a participação no projeto de pesquisa e extensão e a universidade pública.

\section{O PAPEL E O PERFIL DOS JOVENS PESQUISADORES NO PROJETO}

O projeto em tela é desenvolvido desde 2018 na USP e está estruturado em três ações principais: um ciclo de eventos que reúne artistas e acadêmicos para discutir a produção cultural periférica; uma plataforma digital com a sistematização das atividades de ensino, pesquisa e extensão universitárias voltadas para as periferias e favelas; e a realização de um censo domiciliar e sociocultural das comunidades periféricas do entorno de dois campi universitários. O objetivo geral é promover interações e pesquisas que contribuam para aproximar a universidade e as periferias, reconhecer suas produções e ampliar os meios para maior representação dos sujeitos e experiências periféricas na universidade.

O projeto foi idealizado por uma ativista social reconhecida por seu histórico em defesa dos direitos de moradores de favelas, durante sua atuação como titular de uma das cátedras do Instituto de Estudos Avançados da USP e como professora visitante da instituição. Além dela, colaboram com o projeto professores de diferentes unidades da USP, profissionais externos que atuam como consultores, moradores dos contextos pesquisados na posição de articuladores do censo, graduandos, pós-graduandos e pós-doutoranda uspianos na condição de pesquisadores ${ }^{3}$. Os estudantes foram escolhidos em dois processos de seleção (um em dezembro de 2018 e outro em maio de 2019) para o qual concorreram 205 candidatos às 40 bolsas de graduação e pós-graduação então disponíveis.

Entre os documentos para a candidatura, solicitava-se uma carta de motivação sobre o tema das periferias e favelas e suas correspondências com a vida acadêmica, com destaque para a capacitação e as habilidades pessoais que pudessem contribuir com as ações a serem desenvolvidas. Além de currículo e histórico escolar, que serviam de referência para a avaliação posterior em uma entrevista presencial. Ao longo de todo o projeto, 63 pesquisadores foram chamados a atuar nas diferentes ações, sendo que, atualmente, 14 estão envolvidos (11 graduandos, 2 pós-graduandos e 1 pós-doutoranda).

Nos dois processos seletivos, os pesquisadores foram escolhidos com base em critérios que privilegiaram o desempenho acadêmico, a relação pessoal e profissional com as

\footnotetext{
${ }^{3}$ Focalizo, aqui, as narrativas dos graduandos por sua expressividade numérica no projeto e pela possibilidade de pensar seus percursos e projetos de vida em relação com políticas de ação afirmativas nos cursos universitários. Dos 63 pesquisadores que se tornaram bolsistas, 53 cursam/cursavam a graduação, 9 estão/estavam na pós-graduação e 1 faz estágio pós-doutoral. Entre os graduandos, havia 33 moças e 20 rapazes com idades entre 17 e 36 anos, sendo que a maior parte deles tinha entre 19 e 24 anos quando ingressou no projeto (38 no total). Com base na autoclassificação e pertencimento racial, 27 dos estudantes de graduação são negros (pretos e pardos), 25 são brancos e 1 indígena.
} 
periferias, o interesse por questões sociais e a condição socioeconômica (podiam participar apenas graduandos qualificados no programa interno de apoio à permanência estudantil), o que resultou na participação de estudantes de variados cursos, mas, predominantemente, de origem popular, negra e periférica. A equipe se caracterizou, ainda, por sua inexperiência em relação a projetos acadêmicos.

Especialmente por conta da realização do censo nas favelas e periferias vizinhas à USP, que demandou o maior número de bolsistas (foram 56 ao longo do projeto), a idealizadora do projeto investiu na ideia de que a semelhança de perfil socioeconômico de pesquisadores e pesquisados poderia contribuir com o processo de produção de dados, que envolvia contato direto com os moradores e aplicação de questionários nos territórios. Interessava a ela, também, ter jovens negros, de origem popular e periféricos como protagonistas da pesquisa, no intento de propiciar um percurso formativo que incluísse a reflexão sobre as condições sociais que os cercaram por toda a vida.

Esse perfil social que poderia influir na qualidade das relações em campo e, consequentemente, na qualidade dos dados levantados, demandou respostas da coordenação do projeto que não estavam previstas em seu planejamento e que não costumam ser preocupações elementares em uma ação acadêmica. Ajuda financeira para o transporte e alimentação em campo, apoio para a compra de cesta básica familiar nos primeiros meses de pandemia do coronavírus no Brasil e encaminhamentos para atendimento psicoterapêutico dentro e fora do espaço universitário foram algumas das intervenções realizadas. Em determinado momento, os relatos sobre sofrimento mental provocado por alguns aspectos da experiência acadêmica (competição por prestígio entre os estudantes, bloqueios de escrita, desentendimentos com docentes e colegas, pressões e frustrações quanto ao desempenho etc.), assim como pela vivência da juventude no atual contexto (com crises de ansiedade e pânico, por exemplo), desencadearam o convite para que uma profissional especializada em abordagem psicossocial de sujeitos negros e pobres se utilizasse de uma das reuniões regulares do projeto para uma escuta qualificada daqueles jovens.

As reuniões quinzenais ocupam parte da carga de 40 horas mensais cumpridas pelos bolsistas e são dedicadas à leitura de textos teórico-metodológicos, compartilhamento de experiências de campo e desenho de estratégias para a realização da pesquisa. É nessas reuniões que emergem dificuldades para cumprimento de prazos e objetivos da pesquisa, assim como angústias, anseios e cansaços devido ao desgaste físico e emocional de se realizar pesquisa em contextos de vulnerabilidade social.

Ao mesmo tempo, essas reuniões podem ser vistas como reveladoras de aprendizados acumulados pelos pesquisadores com relação às vivências na universidade, nos seus territórios de origem e de pesquisa. Ali, os vínculos afetivos, éticos e políticos 
construídos com as periferias apontam para o desejo de "querer fazer diferença", seja pela expectativa de gerar mudanças locais a partir de dados e reflexões produzidas, seja pelo desejo de construir uma carreira acadêmica/profissional sensível às desigualdades existentes no país.

Alguns desses aprendizados e vínculos foram retomados em momentos que os pesquisadores foram mobilizados a sistematizar a experiência no projeto em relatórios de pesquisa e relatos produzidos para uma publicação. Embora com finalidades e roteiros distintos, essas produções escritas tiveram como ponto comum a reflexão pessoal dos graduandos sobre o processo e os resultados alcançados pela pesquisa, além do impacto na sua formação. São esses textos que tomo agora como narrativas autobiográficas de sujeitos concretos e grafias da vida social de certa parcela da juventude brasileira, no intuito de refletir como marcadores sociais como idade, geração, classe social, raça e território podem se articular na experiência universitária, e influir na percepção dos jovens sobre si mesmos e seus projetos de vida.

\section{JOVENS PESQUISADORES PERIFÉRICOS: NARRATIVAS SOBRE SI E A EXPERIÊNCIA UNIVERSITÁRIA}

O primeiro encontro que reunia os aprovados nos dois processos seletivos do projeto tinha uma dinâmica comum: além da apresentação dos professores, articuladores e consultores envolvidos, cada um dos jovens também fazia uma apresentação de si, destacando suas expectativas de atuação e informações pessoais (idade, formação, histórico profissional ou de ativismo etc.). Nesse momento, invariavelmente, o local de moradia e algum detalhe do percurso até chegar à universidade eram igualmente mobilizados, o que soava como um esforço de visibilizar, diante da equipe, que um perfil socioeconômico específico os levou até ali, tal como preconizavam os critérios de seleção do projeto.

Nesse e em outros momentos que as questões relacionadas ao percurso dos jovens até a universidade apareciam, podia-se perceber que a heterogeneidade de situações presentes periferias urbanas (NASCIMENTO, 2014) se materializava nas biografias desses pesquisadores: alguns com histórico de voluntariado social e engajamento no movimento hip hop e saraus de periferias, pouquíssimos com passagem por escolas particulares, uns com experiências profissionais (em áreas como recepção, produção industrial, eventos e administração), muitos sem nunca ter trabalhado. Mas também era possível perceber dois aspectos comuns: a valorização da chegada no ensino superior (após tentativas frustradas de ingresso, dificuldades financeiras para se dedicar somente ao estudo, poucas pessoas do círculo íntimo que alcançaram essa formação, por exemplo) e o fato de serem os primeiros de suas famílias a ingressarem na universidade, ou mais frequentemente, na universidade 
pública. As famílias eram recorrentemente mencionadas, tanto por conta do orgulho ou surpresa pela presença daqueles jovens no contexto universitário, como por seus arranjos e esforços para fazerem com que os filhos alcançassem o nível superior.

Ao imaginar o que faria ao concluir o ensino médio, pensava em ingressar no mercado de trabalho e pagar uma faculdade. Ainda naquela época não sabia sobre universidades públicas, e nem que a USP, mesmo estando próxima de mim, era uma faculdade. Fui escolhido junto a outros cinco colegas para uma bolsa de pré-iniciação científica [...] a partir daí, conheci a USP Leste, seus cursos e uma iniciativa que estava surgindo, chamada Cursinho Popular EACH-USP (CPE). Já morando na então Vila Guaraciaba, conheci outra iniciativa de cursinho, a Uneafro Brasil. Fui aluno deles e do CPE no meu último ano de escola e, em janeiro de 2018, tive uma das melhores notícias da minha vida, a visualização de um futuro possivel. Consegui, com o apoio de muitos, saltar o grande vão que existia entre mim e a USP, sendo o primeiro da minha família a ingressar no ensino superior (Relato, estudante do $1^{\circ}$ ano de Gestão de Políticas Públicas ${ }^{4}, 21$ anos, junho de 2020, grifos da autora).

Por ser uma mulher negra da periferia de São Paulo, a universidade pública sempre foi algo muito longe da minha realidade. Depois de todo processo e barreiras para chegar na universidade, encontrei outros obstáculos dentro da própria USP. Uma pesquisa como o censo, que tem o objetivo geral de constituir um diagnóstico sociocultural e econômico representativo dos territórios e moradores vizinhos à USP, me mostrou o interesse da universidade por algo que não foi feito antes, pois as relações entre a universidade e os moradores possuem aspectos diferentes das outras regiões. Mesmo estando ao lado, o acesso não é o mesmo do que um morador da Vila Indiana ou moradores de prédios dos condomínios ao redor, alguns moradores não sabiam que a USP era pública. [...] Poder ser convidada a entrar na casa de cada um foi um privilégio que o campo proporcionou, mostrando que alguns alunos da USP tiveram uma origem assim como a deles, mostrando que fui a primeira da família a entrar em uma universidade... Muitos respondiam com sorrisos e brilho nos olhos, nos acolhendo até em nossos desafios pessoais de estar na universidade, falando: "não deve ser fácil, minha filha, mas você consegue" (Relatório de pesquisa, estudante do $2^{\circ}$ ano de Engenharia Elétrica, 25 anos, agosto de 2020, grifos da autora).

Nos dois trechos destacados, nota-se, ainda, que a proximidade geográfica com campus da USP ${ }^{5}$, por si só, não cria expectativas de ingresso entre os moradores de baixa renda do entorno. No primeiro caso, a distância social entre o jovem negro, morador de uma favela próxima ao campus da zona leste, filho de auxiliar de limpeza que estudou até a $4^{\text {a }}$ série do ensino fundamental, foi dirimida com projetos de extensão universitária. No segundo caso, o contato dos moradores de uma favela localizada ao lado do campus Cidade Universitária com uma pesquisadora negra do projeto parecia tornar possível a eles que corpos similares ocupassem aquele espaço na posição de estudantes, ao mesmo tempo que

\footnotetext{
${ }^{4} \mathrm{O}$ estudante em questão cursou dois anos do Bacharelado em Lazer e Turismo, antes de se transferir para o curso de Gestão de Políticas Públicas. Desempenha o papel de articulador local.

${ }^{5}$ Cidade Universitária é o maior campus da USP na capital São Paulo e está localizado no Butantã, bairro que experimenta certa centralidade urbana e que abriga, majoritariamente, moradores ligados às camadas médias e altas. Na vizinhança desse campus e em uma área que é de propriedade mista (parte do Estado, parte da USP), formou-se a favela São Remo, que é um dos territórios estudados pelo censo realizado no âmbito do projeto aqui destacado. Já a EACH (Escola de Artes, Ciências e Humanidades), conhecida também como USP Leste, é o campus mais recente da USP na cidade (foi inaugurado em 2005) e está situado numa região periférica, extremamente populosa e com alta demanda por ensino público de nível superior.
} 
deu um sentido de representatividade à jovem acerca de sua presença na USP, apesar de todas as dificuldades que ela sinaliza quanto ao seu ingresso e permanência.

A partir dos currículos enviados para os processos seletivos é possível apreender que muitos dos jovens foram formados por escolas técnicas públicas e institutos federais e que conciliaram a experiência profissional anterior à universidade com cursos de idiomas (sobretudo inglês e espanhol). Os relatos apontam que alguns passaram por preparação em cursinhos populares (muitos oferecidos pela própria USP para estudantes de baixa renda e egressos de escolas públicas) e por projetos sociais voltados à profissionalização, experimentação artística e prática esportiva. Isso demonstra que os esforços familiares para oferecer aos jovens a melhor formação ao alcance de suas condições materiais encontrava suporte em políticas educacionais de ampliação de ensino técnico gratuito e ações da sociedade civil e do terceiro setor voltadas para as periferias e favelas. Mas também aponta para investimento financeiro nos jovens que eram percebidos com potencial para estudo e postos de trabalho de maior especialização, bem como para arranjos particulares de algumas famílias, tal como a escolha de escolas de ensino médio localizadas em bairros distintos daqueles ondem moram, numa intenção de aproximá-los de equipamentos e infraestruturas percebidas como de melhor qualidade, ou pelo menos, não estigmatizados pela criminalidade, violência e ensino ruim.

Nasci e morei até os quatro anos de idade numa favela chamada Vila Praia, extinta por resultado da desapropriação em massa, que obrigou a minha e centenas de outras famílias a abandonarem suas casas sem nenhum tipo de subsídio. Era localizada na região do Morumbi, zona sul da cidade de São Paulo, bem próximo ao bairro de minha posterior residência: Paraisópolis ${ }^{6}$. Esta que hoje é definida como a segunda maior favela do Estado de São Paulo. Tendo conhecimento sobre o sucateamento do ensino público em favelas, minha mãe sempre optou por me matricular em escolas localizadas nos bairros que ela julgava "melhores". Entretanto, por conta de sua potência populacional, econômica, e sua força comunitária, Paraisópolis sempre mostrou ter diversidade de programas e projetos internos voltados ao estudo, trabalho, esporte, arte e cultura, como reforço escolar, oficinas de artesanato, cursos profissionalizantes, futebol, desenho, entre tantos outros. E tal como correr sobre suas ruas e becos, os programas também me transmitiram sentimento de pertencimento àquele local, pois me apresentaram outras pessoas com carências materiais e familiares iguais às minhas ou, por muitas vezes, piores (Relato, estudante do $2^{\circ}$ ano de Lazer e Turismo, 24 anos, junho de 2020, grifos da autora).

Para os relatórios e relatos, os jovens foram orientados a contemplar aspectos como atividades de formação, atividades de pesquisa, cotidiano do trabalho, relacionamento entre a equipe, histórias de vida conhecidas a partir da pesquisa, aspectos do dia a dia dos territórios, relações entre o projeto e a vida acadêmica ou entre o projeto e a história pessoal, além de outros que considerassem significativos. Evidentemente, a própria demanda pela escrita de textos que seriam avaliados por professores (no caso dos relatórios)

\footnotetext{
${ }^{6}$ Paraisópolis é a segunda maior favela de São Paulo e está localizada na zona sul, tendo no seu entorno alguns dos bairros que concentram populações das camadas médias e altas na cidade.
} 
ou lidos por um público amplo (no caso dos relatos publicados em livro) os impelia a estabelecer considerações positivas sobre a experiência ${ }^{7}$, mas considero que isso não invalida seus esforços em atribuir uma lógica e apresentar relações inteligíveis de acontecimentos por eles vivenciados no projeto, criando um sentido, mesmo que artificial, para o que estava sendo narrado 8 .

A escrita sobre a participação no projeto se tornou, assim, uma oportunidade de refletir sobre a experiência universitária, sendo a referência às marcas sociais que os jovens carregam um aspecto muito recorrente nessa reflexão. Nas narrativas dos jovens, ao mesmo tempo que o projeto aparece como um espaço de acolhimento e valorização dessas marcas, por vezes é lido em contraste com própria universidade, como se fosse descolado daquele espaço. Ou, muitas vezes, o projeto é percebido como uma das poucas ações em que estudantes pobres, negros e/ou moradores de periferias são maioria, atuam juntos e constroem vínculos de pertencimento à universidade a partir desse encontro.

Recebi o chamado para esse projeto em dezembro de 2018 e me inscrevi. Acostumada a não me encaixar na maioria dos editais, fiquei fascinada pela descrição do que seria o projeto e mais ainda quando vi que um dos requisitos era ter uma vivência na periferia. Enfim, os meus 10 anos de Capão Redondo9 pesariam no meu currículo (Relato, estudante do $3^{\circ}$ ano de Letras, 26 anos, junho de 2020, grifos da autora).

Estudei a vida inteira em escola pública e, tal como para muitos jovens moradores do Keralux ${ }^{10}$ a USP era um sonho distante para mim. No entanto, através do cursinho comunitário da FEA-USP, percebi que era possivel conquistar o meu espaço em uma universidade pública. Com muito esforço, ajuda de professores e colegas, consegui entrar no curso de Geologia. O que foi uma grande vitória, e por isso um dos meus maiores desejos era mostrar para outros jovens de periferia que é possivel conquistarmos uma vaga em universidades públicas. Porém, ao entrar na Universidade me deparei com outras dificuldades, como o tempo gasto em transporte público, a carga horária excessiva, as provas, os trabalhos, e a falta de tempo e por isso tive de abrir mão de outros projetos para conseguir permanecer no curso. Depois um tempo me deparei com o censo [...]. Logo tive interesse pela possibilidade de estar em contato com realidades parecidas com a minha (Relato, estudante do $5^{\circ}$ ano de Geologia, 24 anos, junho de 2020, grifos da autora).

\footnotetext{
${ }^{7}$ Para outros, a experiência não foi tão positiva ou não gerou engajamento e interesse suficientes para garantir a permanência no projeto. Dos 50 graduandos que atuaram no censo, 20 ficaram vinculados por até 4 meses, apenas. Entre os motivos elencados para o desligamento (que partiu, majoritariamente, dos bolsistas) estão: a exaustão com o trabalho de campo nos contextos periféricos, a dificuldade de conciliar a atuação no projeto com a vida universitária, a inadaptação às atividades previstas pelo projeto e o interesse por outras oportunidades de pesquisa ou trabalho.
}

${ }^{8}$ Lógica, inteligibilidade, relações, atribuição de sentido são expressões utilizadas por Bourdieu para pensar os conteúdos de entrevistas autobiográficas (1996 [1986], p. 184-185). Creio que, ainda que se refira a outro tipo de instrumento de elaboração de si, essas considerações também podem ser utilizadas para pensar o texto autobiográfico.

${ }^{9}$ Capão Redondo é um bairro da zona sul paulistana bastante estigmatizado por seus índices de violência e pobreza.

10 Jardim Keralux é um bairro da periferia da zona leste de São Paulo que se formou nos anos 1990, a partir de loteamentos vendidos ilegalmente, e ainda passa por processos de consolidação de serviços públicos, infraestrutura e equipamentos urbanos à sua população. 
Este um ano e oito meses de pesquisadora no projeto tiveram diversos impactos na minha formação pessoal e acadêmica. A começar pelo processo de se realizar os objetivos da pesquisa conjuntamente com a equipe, constituida majoritariamente por pessoas negras, que de maneira informal tornou o próprio projeto um lugar de fortalecimento político, somado aos nossos esforços na busca de "espaços pretos" na Universidade e de apoio mútuo para enfrentamentos dia a dia, onde pudemos criar um rede de afeto e cuidado, com nossas festas dos aniversariantes do mês, os almoços comunitários realizados entre todos, a ajuda mútua em conseguir entrevista uns para os outros e para além dos propósitos iniciais do projeto, a possibilidade de nos organizarmos, para promover um evento com temática de negritude na EACH/USP no mês de Novembro. [...] A partir desta experiência fui levada a reelaborar questões de minha subjetividade e vivência, sendo também importantes para a produção acadêmica de conhecimento sobre o mundo e a realidade que vivenciei (Relatório de pesquisa, estudante do $4^{\circ}$ ano de História, 22 anos, agosto de 2020, grifos da autora).

O fato de compartilharem perfil socioeconômico e experiências comuns quanto ao acesso e à permanência aproximou esses jovens, fortaleceu relações de amizade, desencadeou outros projetos em comum. Mas essa aproximação se deu também pelas percepções similares sobre o elitismo da USP, a falta de docentes negros e de origem popular naquela universidade (ou pelo menos interessados pelas questões que cercam estudantes com esse perfil social), as poucas oportunidades que os estudantes tiveram para atuar em pesquisas aplicadas com foco em populações periféricas ou para debater em sala de aula temas que se cruzam com suas biografias: raça, gênero, desigualdades no Brasil e na América Latina, pobreza, cultura periférica e vulnerabilidade social ${ }^{11}$.

Todos os graduandos do projeto ingressaram na USP beneficiados por algum tipo de ação afirmativa para estudantes historicamente alijados do acesso ao ensino superior, tendo em vista que esse tipo de política é praticada na instituição desde 2006 com a bonificação de pontos no vestibular para egressos de escolas públicas, e a partir de 2016, passou a considerar as cotas para autodeclarados pretos, pardos e indígenas que tenham cursado integralmente o ensino médio na rede pública ${ }^{12}$. Os jovens experimentaram uma universidade que, desde então, tem pelo menos $25 \%$ de estudantes oriundos de escolas públicas e metade deles identificados como negros. Em 2020, esse percentual alcançou cerca

\footnotetext{
11 Os descontentamentos foram expressados durante a reunião de escuta dos pesquisadores que contou com a participação de uma psicóloga. Para a citação dos temas, utilizo como referência uma atividade de avaliação sobre o projeto, realizada em julho de 2019. Com a participação de 19 pesquisadores (17 graduandos e 2 pós-graduandos), a atividade incluía uma pergunta sobre temas que poderiam ser abordados nas reuniões regulares e contribuir com a formação dos estudantes.

12 Dois pontos merecem ser ressaltados quanto ao atraso da USP nessa seara. O primeiro é que o debate sobre políticas afirmativas para a população negra e indígena no nível superior ganhou proporções expressivas a partir das propostas brasileiras na III Conferência Mundial contra o Racismo em Durban, no ano de 2001, sendo as primeiras cotas raciais implementadas já em 2003, pela Uerj (Universidade do Estado do Rio de Janeiro) (SILVA, 2003). O segundo é que a USP só adotou a reserva de vagas para negros e indígenas a partir de sua adesão, em 2015, ao Sisu (Sistema de Seleção Unificada), criado pelo Ministério da Educação para que as instituições públicas de ensino superior ofereçam vagas nos seus cursos de graduação aos estudantes que participam do Enem (Exame Nacional do Ensino Médio).
} 
de $48 \%$ de egressos da rede pública e, entre eles, $44 \%$ de pretos, pardos e indígenas, segundo autodeclaração ${ }^{13}$.

Os apontamentos dos graduandos sobre a experiência universitária estão para além da reivindicação da maior presença de sujeitos pobres e negros no nível superior, ainda que ela exista. Eles se estendem para o modo como os pilares da universidade (ensino, pesquisa e extensão) estão organizados. Dizem respeito à forma como os concursos docentes são estruturados, aos critérios de distribuição de bolsas de pesquisa e estudo, aos conteúdos curriculares, aos aportes teórico-metodológico e objetivos das pesquisas acadêmicas, às vivências, histórias e conhecimentos que são compartilhados e valorizados.

As respostas que esses jovens pesquisadores apresentam aos próprios questionamentos sobre a universidade passam por estratégias coletivas de discussão, apoio mútuo e participação institucional, e, obviamente, não se esgotam nas redes e iniciativas desencadeadas pelo projeto. Vários deles atuam em coletivos discentes voltados para a discussão da permanência estudantil e experiência universitária com focos e/ou intersecções com as questões raciais, de classe, gênero e sexualidade ${ }^{14}$. Nesses coletivos, à identidade de estudante se somam e se cruzam os pertencimentos e demandas de negros, mulheres, LGBTs, pobres e moradores de periferias e favelas.

Ganhei ciência do projeto a partir do chamamento da minha atual supervisora de campo ao Coletivo Denegrir (grupo de negras e negros na EACH da USP), informando sobre oferta de bolsas para estudantes moradores de periferias para um projeto nas favelas vizinhas às USPs Leste e Cidade Universitária. Nada mais significativo, portanto, do que tomar conhecimento de uma ação que visa, além de gerar dados sobre os objetos de estudo, ao estreitamento das relações da universidade com as comunidades do entorno através do coletivo negro que resiste dentro da escola com maior número de estudantes negros e de escolas públicas da USP. (...) É importante ressaltar que o projeto criou pontes entre indivíduos e grupos que até então não tinham contato uns com os outros e que provavelmente estabelecerão uma relação de longo prazo. Falando especificamente do recorte da equipe atuante no Jardim Keralux, composta, majoritariamente, por não brancos, as próprias pessoas que trabalharam no censo são um bom exemplo. Por conta de a USP ser um ambiente extremamente elitizado e branco, que vem sendo pressionado para a diversificação da sua comunidade e lentamente buscar por essa mudança, alunos negros de baixa renda nem sempre estão conectados para viabilizar a criação de uma rede de fortalecimento. Dessa forma, o perfil dos bolsistas contribuiu para que essa e outras ligações fossem feitas $e$ desencadeou ações e projetos paralelos à pesquisa (Relato, estudante do $3^{\circ}$ ano de Gestão de Políticas Públicas, 20 anos, junho de 2020, grifos da autora).

\footnotetext{
13 Para acesso aos dados, ver: https://jornal.usp.br/especial/modelo-de-inclusao-adotado-pela-uspfoca-no-aluno-de-escola-publica/ e https://jornal.usp.br/institucional/usp-alcanca-meta-de-inclusaosocial-em-2020-e-tem-mais-alunos-de-escolas-publicas/.

${ }^{14}$ O mapeamento realizado para a criação da plataforma digital com as ações de pesquisa, extensão e ensino da USP voltadas para as periferias identificou, em 62 coletivos discentes organizados a partir de marcadores sociais, sendo 15 deles coletivos negros. Ver: www.conexoesperiferias.iea.usp.br.
} 
A chegada desses jovens no contexto universitário indica que o aumento da escolarização e a busca pela alta especialização profissional passaram a integrar seus projetos de vida ${ }^{15}$, numa ampliação de expectativas, oportunidades e elaboração de futuros possíveis, quando pensados em relação aos projetos de seus familiares e de outras gerações de jovens pobres e negros. As narrativas autobiográficas dos graduandos do projeto expressam sonhos, metas e estratégias individuais e coletivas, investimentos financeiros e emocionais de suas famílias, redes de fortalecimento e apoio mútuo dentro e fora da universidade, reflexões sobre suas vidas e mesmo sobre o que pretendem para o futuro, apesar das dificuldades de ordem objetiva e subjetivas que enfrentam.

E uma vez que a universidade pública compõe uma dimensão importante da vivência da juventude por parte desses sujeitos, por ser o local de profissionalização, assim como de socialização, de redes de afeto, (re)elaboração de subjetividades e vivências, ela é foco de reflexão e intervenção. A educação parece ocupar um lugar central na vida desses jovens, e a universidade pública também. Trata-se de pensar qual é função e o sentido que conferem à universidade, qual é o papel que atribuem a si mesmos nessa instituição e, igualmente, que usos fazem e querem fazer da do espaço acadêmico no cotidiano de suas vidas, formação e atuação profissional.

A universidade pública que desejam e disputam, tal como qualquer instituição de ensino, é viva, complexa e marcada por uma intensa produção de conhecimentos e de formas de representação da realidade, muitas vezes contraditórias. Essa universidade vivenciada pelos jovens enfocados é atravessada pelo debate em torno das políticas afirmativas no ensino superior brasileiro, que coloca uma série de questões de ordem política, jurídica, econômica e acadêmica, tais como: a reorganização administrativoinstitucional, o conteúdo e a qualidade do ensino, as ações de permanência estudantil e os projetos científico-acadêmicos que busquem ser inclusivos ${ }^{16}$.

\footnotetext{
${ }^{15}$ De acordo com Gilberto Velho (1994), um projeto é um conjunto de prospecções, baseadas em deliberações de escolhas dentro de um quadro sociocultural e um campo de possibilidades estabelecidos, a partir do qual os indivíduos podem criar identidades para si, alimentar visões de futuro e estabelecer estratégias para alcançar seus objetivos. A partir dessas formulações, Juarez Dayrell (2005) sintetizou que um projeto de vida pode ser compreendido como uma ação de escolha do indivíduo dentre os futuros possíveis numa dada realidade, podendo ter caráter individual e coletivo, e modificar-se à medida que os sujeitos amadurecem e há mudança nos seus campos de possibilidades. Já Mauricio Perondi (2020) considera que, associado aos jovens, projeto de vida inclui a possibilidade de se ter esperança sobre o presente e o futuro, tendo em vista que se trata de uma parcela da população que, em muitos cenários, não têm acesso a direitos básicos.

${ }^{16}$ Ver, por exemplo, os trabalhos reunidos no livro Acesso e permanência da população negra no ensino superior, organizado por Lopes e Braga, acerca das primeiras experiências de implementação de ações afirmativas nas universidades públicas brasileiras (2007) e as discussões apresentadas por Dias Sobrinho sobre a configuração da universidade pública após o acúmulo desse processo (2015). O verbete sobre universidade organizado por Andrade (2020) também passa por essas questões.
} 
Sendo assim, ao mesmo tempo que se deparam como uma instituição que está tensionada por processos de democratização do acesso e inclusão grupos sociais historicamente marginalizados, é a partir de suas marcas sociais que esses jovens disputam a universidade pública como lócus de produção de conhecimento. Se os marcadores sociais só fazem sentido quando articulados na experiência do indivíduo, nos seus discursos (ou narrativas) e na sua atuação política ${ }^{17}$, raça, classe e território parecem se encontrar nos jovens para dar significado à experiência universitária. Um significado que passa pela consideração de algumas pautas políticas e sociais, bem como pela preocupação com a produção de conhecimento aplicado e por certo engajamento pessoal/profissional.

o projeto viabilizou o desejo que sempre tive em mente quando pisei nessa instituição de ensino, de retribuir à comunidade o privilégio de estar na maior universidade da América Latina (Relato, estudante do $2^{\circ}$ ano de Arquitetura e Urbanismo, 24 anos, junho de 2020, grifos da autora).

Uma das principais motivações para que eu quisesse desenvolver atividades de pesquisa foi, antes de tudo, conseguir ocupar espaços que as pessoas menos favorecidas não conseguem. Acredito que represento uma parcela bem grande da população, que simplesmente não é ouvida e nem sequer consegue estudar e mudar a própria realidade. Quando um jovem pobre e negro, como eu, ocupa um espaço em uma universidade como a USP, e tem a oportunidade de se tornar um pesquisador, não há mais a chance de não querer seguir este caminho, porque ele nos foi negado por tempo demais e sinto o dever de possibilitar que outros como eu adentrem esses espaços (Relato, estudante do $4^{\circ}$ ano de Gestão de Políticas Públicas, 25 anos, junho de 2020, grifos da autora).

As narrativas dos jovens sobre si mesmos, o projeto e a universidade são muito positivas. Há certo orgulho por terem se tornado universitários em uma instituição pública e, principalmente, por permanecerem. A participação no projeto de pesquisa e extensão gera aprendizados de cunho teórico e metodológico, além de um encontro de saberes e vivências entre a equipe, assim como entre cada jovem e os sujeitos dos contextos de pesquisa. Quanto à universidade, à despeito das críticas e reivindicações que os jovens fazem, este parece ser um espaço pelo qual vale a pena a disputa, seja de maneira individual ou coletiva.

A experiência universitária marca positivamente a vivência da juventude e os percursos desses jovens. Do modo como deram visibilidade às suas narrativas nos seus relatórios e relatos, não parece haver mais chance de não quererem para si e seus iguais esse caminho.

\section{CONSIDERAÇÕES FINAIS: DAS NARRATIVAS AUTOBIOGRÁFICAS ÀS GRAFIAS DE UMA GERAÇÃO}

Uma narrativa pode ser entendida como a perspectiva do indivíduo sobre a realidade que vive, a partir de uma lente atual, a do momento em que organiza e dá sentido à sua história de vida (WELLER, 2014). Além disso, acessar narrativas é acessar visões de

\footnotetext{
${ }^{17}$ Zamboni, 2014.
} 
mundo e percursos biográficos que dizem respeito não apenas à história individual, mas ao meio social, cultural e histórico de quem narra. Sendo possível, por meio delas, apreender "distintas experiências individuais e coletivas, como também transformações na estrutura social e consequências dessas mudanças na organização da vida cotidiana" (WELLER, 2014, p. 357).

Nesta análise, em particular, as narrativas são lidas a um só tempo como narrativas autobiográficas de jovens e grafias da vida social de certa parcela da juventude brasileira (pobre, negra e moradora de periferias e favelas), cuja experiência geracional passa pelo acesso à universidade no cenário recente. Além do componente etário, esses indivíduos compartilham situações de classe, local de moradia, pertencimento racial e a chegada na universidade pública no contexto de políticas de ações afirmativas para grupos sociais periféricos.

Ainda que seja preciso matizar que os percursos juvenis não podem ser percebidos de maneira unívoca, as narrativas aqui apresentadas sugerem que a articulação entre classe social, raça e territórios conforma uma pista importante para ler a experiência universitária dos jovens pesquisadores, assim como para compreender a vivência da juventude por pobres, negros e moradores de periferia numa chave que inclui a universidade não apenas como parte de seus projetos de vida, mas também como uma dimensão central para disputar suas possibilidades de ser e estar no mundo.

\section{REFERÊNCIAS}

ANDRADE, Giovana de. "Universidade". In: PERONDI, M. et. al. Juventudes: entre A \& Z. Porto Alegre: Cirkula, 2020. p. 431-434.

BOURDIEU, Pierre. A ilusão biográfica. In AMAD0, J.; FERREIRA, M. Usos e abusos da história oral. Rio de Janeiro: Fundação Getúlio Vargas, 1996 [1986]. p. 183-191.

CAMACHO, Luiza. A ilusão da moratória social para os jovens das classes populares. In: SPOSITO, M. Espaços públicos e tempos juvenis. São Paulo: Global, 2007. p. 135-158.

DAYRELL, Juarez. Por uma pedagogia da juventude. Onda Jovem, São Paulo, n.1, p. 34-47, 2005.

DIAS SOBRINHO, José. Universidade fraturada: reflexões sobre conhecimento e responsabilidade social. Avaliação (Campinas), v. 20, n. 3, p. 581-601, 2015.

DOMINGAS, Gislei; SCHIMIT, Tiago. Geração. In: PERONDI, M. et. al. Juventudes: entre A \& Z. Porto Alegre: Cirkula, 2020. p. 226-230.

FEIXA, Carles. De jóvenes, bandas y tribus: Antropología de la Juventud. Barcelona: Ariel, 1999.

FELIX, João B. Hip hop: cultura e política no contexto paulistano. Curitiba: Appris, 2018. 
FRIGOTTO, Gaudêncio. "Juventude, trabalho e educação no Brasil: perplexidades, desafios e perspectivas". In: NOVAES, R.; VANNUCHI, P. Juventude e Sociedade: trabalho, educação, cultura e participação. São Paulo: Editora Fundação Perseu Abramo, 2004. p. 180-216.

GUIMARÃES, Angela. Dilemas da vivência da juventude negra no Brasil. In: PAPA, F.; FREITAS, M.V. Juventude em pauta: políticas públicas no Brasil. São Paulo: Peirópolis, 2011. p. 307-319.

KOFES, Sueli; MANICA, Daniela. Vida e grafia: narrativas antropológicas entre biografia e etnografia. Rio de Janeiro: Lamparina, 2015.

LOPES, Maria Auxiliadora; BRAGA, Maria Lucia. Acesso e permanência da população negra no ensino superior. Brasília: MEC, 2007.

PASSOS, Joana et al. 0 impacto das ações afirmativas no currículo acadêmico do ensino superior brasileiro. Revista da Associação Brasileira de Pesquisadores/as Negros/as (ABPN), v. 8, n. 19, p. 08-33, 2016. Disponível em: <https://abpnrevista.org.br/index.php/site/article/view/23>. Acesso em: jan. 2021.

MANNHEIM, Karl. El problema de las generaciones. Revista Reis, n. 62, p. 193-242, 1993 [1928].

NASCIMENTO, Erica P. Periferia. In: SILVA, C. (org.). Africanidades e relações raciais: insumos para políticas públicas na área do livro, leitura e bibliotecas no Brasil. Brasília: Fundação Palmares, 2014, p. 46.

NOVAES, Regina. Políticas de juventude no Brasil: continuidades e rupturas. In: FAVÉRO, 0. et al. Juventude e Contemporaneidade. Coleção Educação para Todos. Brasília, UNESCO/MEC/ANPEd, 2007. p.253-275.

Conectados globalmente, coletivos juvenis agem na realidade de seus territórios Entrevista especial, 2019. Disponível em: http://www.ihu.unisinos.br/159-noticias/entrevistas/589351conectados-globalmente-coletivos-juvenis-agem-na-realidade-de-seus-territorios-entrevista-especialcom-regina-novaes. Acesso em: janeiro de 2021.

PERONDI, Mauricio. Projeto de vida. In: PERONDI, M. et. al. Juventudes: entre A \& Z. Porto Alegre: Cirkula, 2020. p. 359-364.

SAGGESE, Gustavo et. al. Marcadores sociais da diferença: gênero, sexualidade, raça e classe em perspectiva antropológica. São Paulo: Terceiro Nome, 2018.

SILVA, Cidinha da. "Ações afirmativas em educação: um debate para além das cotas". In: SILVA, Cidinha da. Ações afirmativas em educação: experiências brasileiras. São Paulo: Summus, 2003. p. 17-38.

SOUTO, Jane. Os outros lados do funk carioca. In: VIANNA, Hermano (Org.). Galeras cariocas: territórios de conflitos e encontros culturais. Rio de Janeiro: Editora UFRJ, 1997, p. 59-93.

VELHO, Gilberto. Projeto e metamorfose: antropologia das sociedades complexas. Rio de Janeiro: Jorge Zahar, 1994.

WELLER, Vivian. Narrativas biográficas de jovens: o que seus destinos revelam. In: CARRANO, P.; FAVERO, 0. Narrativas juvenis e espaços públicos. Niterói: Editora da UFF, 2014. p. 355-374. 
ZAMBONI, M. Marcadores Sociais da Diferença. Sociologia: grandes temas do conhecimento (Especial Desigualdades). São Paulo, v. 1, p.14 - 18, 2014. Disponível em: $<$ http://www.agenciapatriciagalvao.org.br/dossie/wp-

content/uploads/2015/07/ZAMBONI MarcadoresSociais.pdf> . Acesso em: janeiro de 2021.

Recebido em 31 de janeiro de 2021. Aprovado em 05 de agosto de 2021. 